\title{
Safety management and formal safety assessment: a study of the Taiwan area
}

\begin{abstract}
This work demonstrates the benefits of the application of the Formal Safety Assessment methodology for aviation safety in the Taiwan area. This study used Taiwan's aviation safety statistics to analyze the factors relating to aviation accidents. Then, a costbenefit assessment of the Formal Safety Assessment was adopted to make practicable decisions. The statistics indicated that most aviation accident cases were concentrated in airports, and were mostly caused by human factors. In addition, these results suggest that an appropriate adaptation of the Formal Safety Assessment methodology can enhance decision making in aviation safety management.
\end{abstract}

Keywords: aviation safety, formal safety assessment (FSA), air accident, cost benefit assessment, aerodrome facilities
Volume I Issue 4 - 2017

\author{
Hsin Hung Cheng,' Kwan Ouyang ${ }^{2}$ \\ 'Maritime and Port Bureau, Ministry of Transportation and \\ Communication, Taiwan \\ ${ }^{2}$ Department of Marine Engineering, Taipei University of \\ Maritime Technology, Taiwan
}
Correspondence: Kwan Ouyang, Department of Marine Engineering, Taipei University of Maritime Technology, No.212, Sec. 9, Yanping N. Rd., Shilin Dist., Taipei City II I74, Taiwan(R.O.C.), Tel +886-2-28I0-2292\#5020, Fax +886-2-28I0- 6688, E-mail f0898@mail.tcmt.edu.tw

Received: July 18, 2017 | Published: December 20, 2017
Abbreviations: SMS, safety management systems; MSC, maritime safety committee; FSA, formal safety assessment

\section{Introduction}

As an island nation, Taiwan, has established an aviation safety management method that is second to none. To maintain the safety of international traffic for many countries, in addition to land transport, various guidelines have been proposed for maritime and aviation transportation. The Safety Management System (SMS) framework has been of primary importance in the field of aviation safety for many years. ${ }^{1}$ However, it is often suggested that ineffective safety management methods may be a sign of a greater problem. In relation to SMS, it is often difficult to identify the most important issues, especially when employing a cost-benefit assessment. Therefore, as a basic necessity, cost-benefit assessment is an approach that those in aviation safety management cannot do without. ${ }^{2}$ To minimize maritime casualties, the United Nations Maritime Organization, at the 74th meeting of the Maritime Safety Committee, used the Formal Safety Assessment (FSA) as a risk assessment method for the prevention and analysis of maritime casualties. ${ }^{3,4}$ The most important feature of the FSA methodology is that it provides guidelines for a reasonable, sensible, and systematic approach to safety. ${ }^{5}$ Furthermore, this method can help identify priorities that should be addressed. Therefore, our study provides insight into aviation safety management methodologies to reduce the number of air accidents and improve aviation safety.

\section{Fsa methodology}

The objective of this paper is to utilize FSA for analyzing air accident characteristics in the vicinity of Taiwan in terms of aviation safety, and thus to provide pertinent information relating to aviation safety management performance.

The flowchart of FSA is displayed in Figure 1. FSA includes hazard identification, risk assessment, risk control options, costbenefit assessment, and decision-making, and the procedures involved can be described as follows: a. Hazard identification: analyze all the threats to people and property.

b. Risk assessment: identify the risk probability and the impact on safety.

c. Risk control option: provide methods to reduce this risk.

d. Cost-benefit assessment: evaluate the cost of the assessment method and provide advice.

e. Decision-making: discuss the degree of risk that can be sustained.

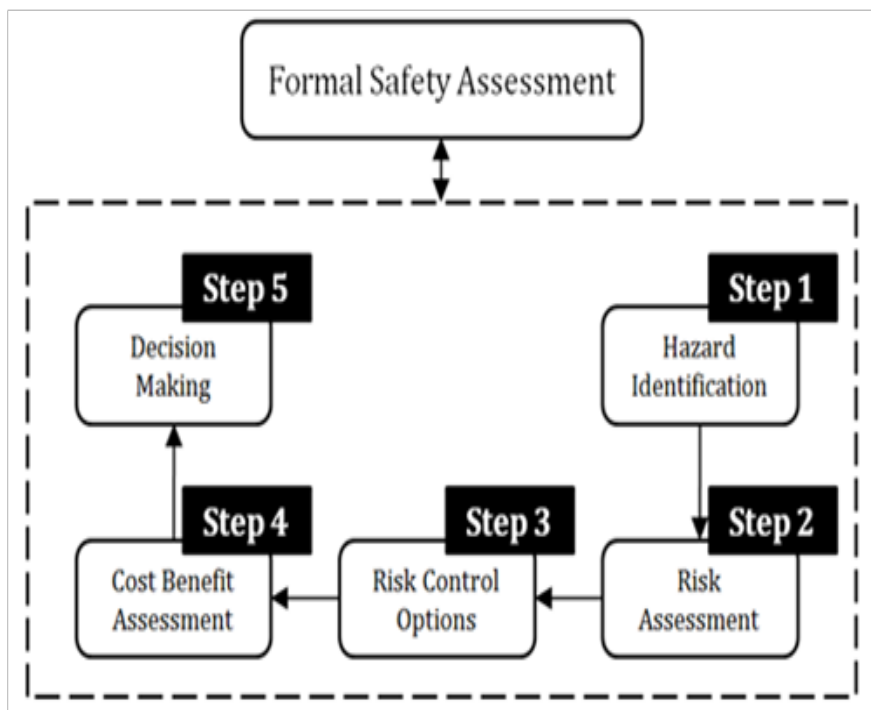

Figure I Flowchart of Formal Safety Assessment.

In previous studies ${ }^{6,7}$ FSA was considered as a prominent method of ensuring aviation safety. Therefore, we utilized the first step of the FSA guidelines to address and identify the hazards in the aviation industry, including human, ${ }^{8,9}$ climate, ${ }^{10}$ machine, ${ }^{11,12}$ airport, ${ }^{13,14}$ and other contributing factors. ${ }^{15,16}$ It is worth mentioning 
that through comparing SMS Risk Management methodology and FSA, we concluded that both are applicable management methods for transportation. They both outline the risk and hazard issues of safety management to prevent the occurrence of incidents. ${ }^{4,17}$ On the other hand, there are dissimilarities between the two methodologies, in that only FSA addresses cost-benefit assessment, especially in relation to other countries. ${ }^{18,19}$ Therefore, we analyzed FSA as set of guidelines that is widely applied in maritime safety to compliment SMS Risk Management methodology as an aviation safety management method. It should be noted that in FSA, there is a correlation between risk control options and cost-benefit assessment. FSA cannot be applied in the absence of both of these key factors.

\section{Analysis}

The second step of the FSA guidelines was employed to conduct a risk assessment for aviation safety. Our study utilized data from 2007 to 2016 from the Civil Aviation Authority of Taiwan to analyze air accidents in the vicinity of Taiwan. ${ }^{20}$ The data indicated that 68 aircraft incidents occurred. Aside from the cases in the Taiwan area, there were 55 air accidents for analysis. In these data, 31 of the cases took place in airports $(56.4 \%)$, followed by 17 cases in mountainous areas $(30.9 \%)$, and 7 cases in oceanic areas $(12.7 \%)$. Figure 2 displays a map and the percentages of the principal causes of air accidents that occurred in the Taiwan area. Furthermore, airport factors constituted the predominant cause, followed by human (16cases), climate (5cases), machinery (6cases), and other factors (4cases). Therefore, our analysis indicates that aviation accidents predominantly occurred either at airports or in mountainous areas. The major causes of the accidents were human factors. Table 1 provides an overview of air accidents, their situations, and statistics.

Table I Air accidents statistical data (2007-20I6)

\begin{tabular}{llllll}
\hline Area IItems & Human & Climate & Machine & Others & Total \\
\hline Airport & 16 & 5 & 6 & 4 & $31(56.4 \%)$ \\
Mountains & 12 & 1 & 2 & 2 & $17(30.9 \%)$ \\
Sea & 2 & 1 & 1 & 3 & $\mathbf{7}(12.7 \%)$ \\
Total & $\mathbf{3 0 ( 5 4 . 5 \% )}$ & $\mathbf{7 ( 1 2 . 7 \% )}$ & $\mathbf{9 ( 1 6 . 4 \% )}$ & $\mathbf{9 ( 1 6 . 4 \% )}$ & $\mathbf{5 5}$ \\
\hline
\end{tabular}

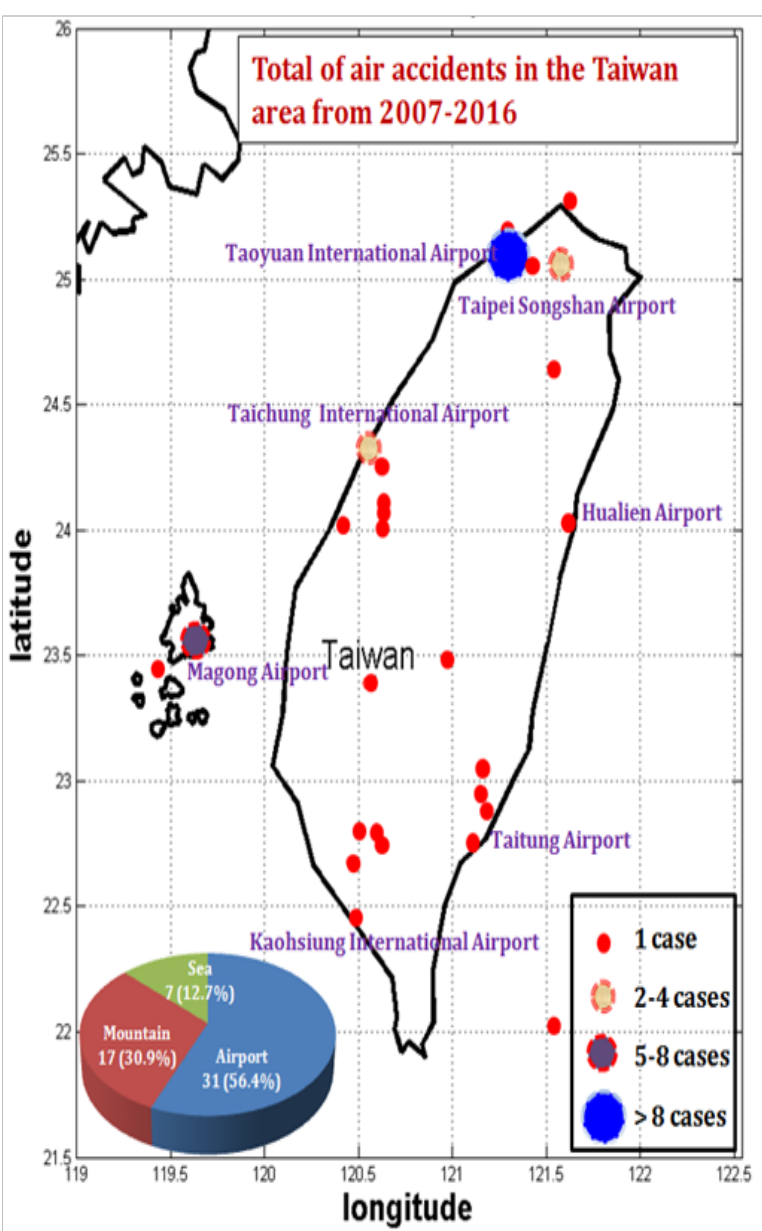

Figure 2 Map and percentage of the principal causes of air accidents location in the Taiwan area.

\section{Discussion and results}

According to the aforementioned statistics, to identify priority issues, we utilized the third step of the FSA guidelines to address the threats for aviation management: risk control options. The statistical data displayed in Table 1 evince that Taiwan's aviation accidents were concentrated in airports, and most were caused by humans. Therefore, we identified two management methods to be employed as our preferred choices, in both personnel training and aerodrome facilities. After analyzing the risk control options, we utilized the decision tree method to apply the fourth step in the FSA guidelines, and obtained a recommended outcome that was reasonable, sensible, cost effective and systematic. An investment decision tree theoretical model that illustrates the relationships explored in this study is presented in Table 2. Taking personnel training as an example, we analyzed two items of investment in this area. Then, according to the Taiwanese government's business indicators database and airline companies' reward statements, we analyzed this information in terms of profit maximization. For these two items, we identified investing in personnel training as the best choice. After that, the final step of the FSA guideline was examined to make a reasonable and sensible decision. The results of the cost-benefit assessment were not identified in SMS risk management process, because as previously stated, FSA considers cost-benefit assessment but SMS does not. To establish an effective management method for aviation safety, a cost-benefit assessment must be included, or any decision could be unrealistic for application in the aviation industry. Overall, aircraft and vessels are important means of transportation, and they require considerable funding. In the future, reasonable and sensible decisions are required in aviation and maritime safety management. Therefore, we evinced the benefits of the application of the FSA guidelines, not only to maritime safety management, but also to all aspects of aviation safety management. The following summary provides insight into the proposed FSA methodology: 
A. Identify the hazard and then analyze the risks.

B. Include a cost-benefit assessment for the assessment of risk control options.

Table 2 Investment decision tree
C. According to the cost-benefit analysis, identify solutions in order of priority.

D. Make a decision based on a reasonable assessment of the various options.

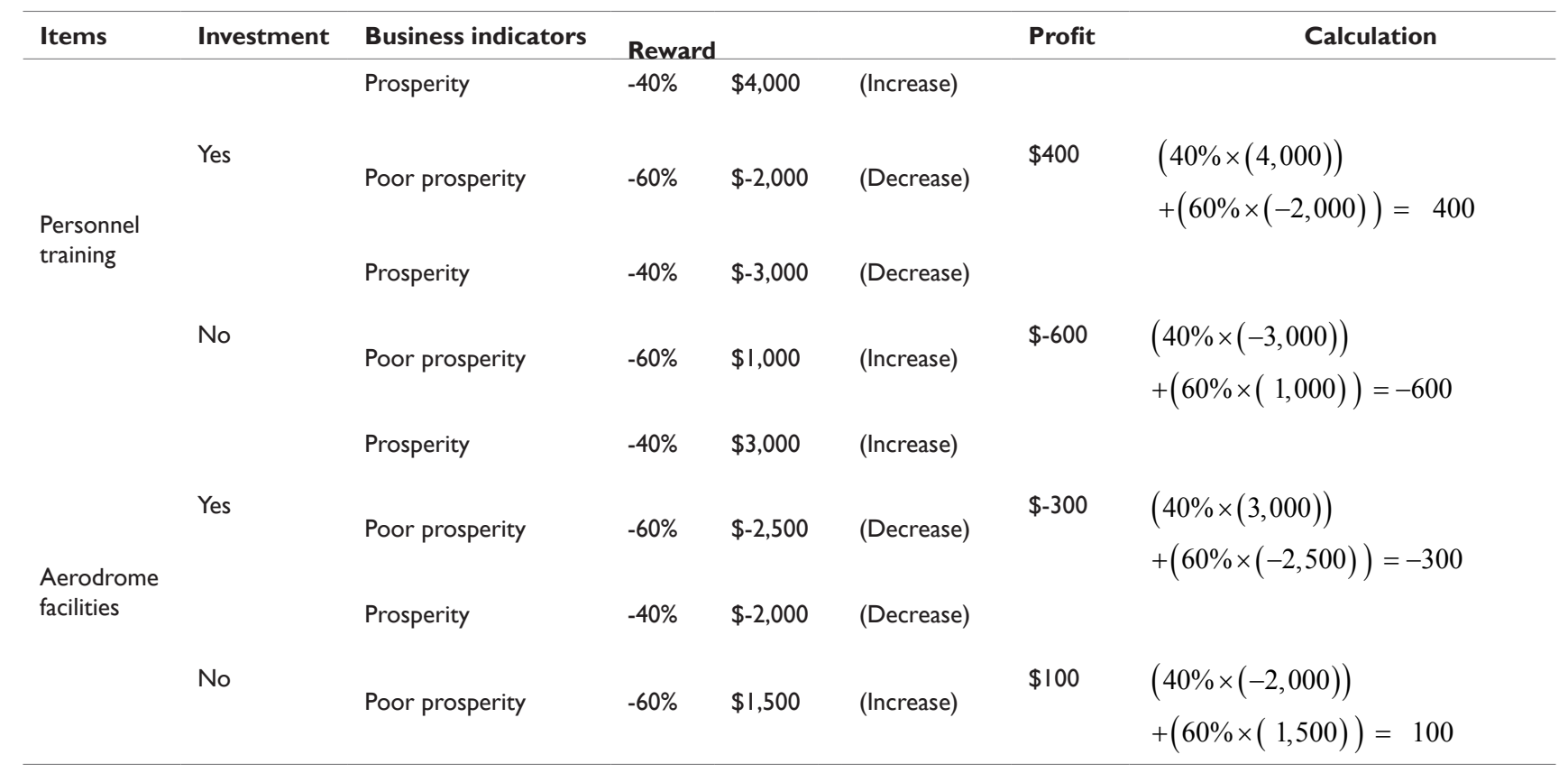

\section{\$, NTD Billion}

\section{Conclusion}

We have adapted the FSA approach for aviation safety in the Taiwan area. In our study, Taiwan's aviation accidents were mostly concentrated at airports, and most were caused by human factors. It was observed from statistical data that the cost-benefit assessment employed in the FSA method can provide solutions for decisionmaking in terms of aviation safety. The FSA methodology should be considered not only as the most widely applied method of improving maritime safety, but as a potentially beneficial approach for aviation safety. Finally, we believe the FSA methodology can connect two important fields: aviation safety and maritime safety.

\section{Acknowledgements}

None.

\section{Conflict of interest}

Author declares that there is no conflict of interest.

\section{References}

1. Leib S, Lu CT. A gap analysis of airport safety using ICAO SMS perspectives: A field study of Taiwan. Journal of Aviation Technology and Engineering. 2013;2(2):63-70.

2. Gillen D, Morrison WG. Aviation security: Costing, pricing, finance and performance. Journal of Air Transport Management. 2015;48:1-12.

3. Psaraftis HN. Formal Safety Assessment: an updated review. Journal of marine science and technology. 2012;17(3):390-402.

4. Kontovas CA, Psaraftis HN. Formal safety assessment: A critical review. Marine Technology. 2009;46(1):45-59.

5. Montewka J, Goerlandt F, Kujala P. On a systematic perspective on risk for formal safety assessment (FSA). Reliability Engineering \& System Safety. 2014;127:77-85.

6. Yadav DK, Nikraz H. Implications of evolving civil aviation safety regulations on the safety outcomes of air transport industry and airports. Aviation. 2014;18(2):94-103.

7. Kontovas CA. Formal Safety Assessment Critical Review and Future Role. Diploma Thesis, National Technical University of Athens, Greece; 2005. 163 p.

8. Aurino DEM. Human factors and aviation safety: what the industry has, what the industry needs. Ergonomics. 2000;43(7):952-959.

9. Liou JJ, Yen L, Tzeng GH. Building an effective safety management system for airlines. Journal of Air Transport Management. 2008;14(1):20-26.

10. Kushwaha M, Sharma SK. Impact of Environmental Factors on Aviation Safety. Advances in Aerospace Science and Applications. 2014;4(1):73-78.

11. Bin Y, Yanpei Z. Icing certification of civil aircraft engines. Procedia Engineering. 2011;17:603-615.

12. Hepperle M. Electric Flight - Potential and Limitations. Energy Efficient Technologies and Concepts of Operation. Portugal; 2012. p. 30.

13. Čokorilo O. Environmental Issues for Aircraft Operations at Airports. Transportation Research Procedia. 2016;(14):3713-3720.

14. Xianfeng L, Shengguo H. Airport safety risk evaluation based on modification of quantitative safety management model. Procedia engineering. 2012;43:238-244.

15. Maria GD. Human-Machine Interaction in Aviation: A Future Threat or Resource. American Journal of Science and Technology. 2016;3(1):25-42. 
16. Milan Janic. An assessment of risk and safety in civil aviation. Journal of Air Transport Management. 2000;6(1):43-50.

17. Kuusisto A. Safety management systems: Audit tools and reliability of auditing. Thesis for the degree of Doctor of Technology. Tampere University of Technology, VTT Publications, Finland; 2000. 222 p.

18. Stewart MG, Mueller J. A risk and cost-benefit assessment of United States aviation security measures. Journal of Transportation Security. 2008;1(3):143-159.
19. Stewart MG, Mueller J. A risk and cost-benefit assessment of Australian aviation security measures. Security Challenges. 2008;4(3):45-61.

20. Flying safety statistics. Aviation Safety Council. Taiwan; 2007-2016. 86 p. 